\title{
Strategies for Global Elimination of Chronic HBV Infection: 2019 Update
}

\author{
Shevanthi Nayagam ${ }^{1,2} \cdot$ Mark Thursz $^{1}$ \\ Published online: 5 August 2019 \\ (C) The Author(s) 2019
}

\begin{abstract}
Purpose of Review With just over a decade to go before the WHO 2030 hepatitis elimination targets, this review takes a global perspective at the major challenges standing in the way of hepatitis B virus (HBV) elimination and discusses potential innovative solutions on the horizon for use in high burden settings.

Recent Findings Universal HBV infant vaccination has been an incredible success. However, in order to reach the elimination targets, efforts now need to urgently focus on scaling up HBV prevention of mother-to-child (PMTCT) interventions, particularly in sub-Saharan Africa and increasing population level testing and treatment.

Summary Innovative outreach strategies, simplified diagnostics and novel biomarkers and integration of systems are promising solutions to allow HBV elimination to be reached in an effective and affordable way. This should go alongside careful financing, policy planning and establishment of strong surveillance systems.
\end{abstract}

Keywords Hepatitis B · Vaccination · Elimination · Antiviral therapy

\section{Introduction}

Despite being the seventh leading cause of mortality globally, viral hepatitis has historically attracted very little global political attention and continues to remain out of the remit of largescale funding organisations. The last decade, however, has witnessed an increasing political momentum for viral hepatitis, which has been accompanied or even, accelerated, by a step-change in therapeutic options for hepatitis C. In 2016, The World Health Assembly endorsed the first global hepatitis elimination targets which called for a $65 \%$ reduction in hepatitis-related mortality and $90 \%$ reduction in incidence of hepatitis by 2030 , an impact which was considered to represent elimination of viral hepatitis as a public health threat.

This article is part of the Topical Collection on Hepatitis B

Shevanthi Nayagam

s.nayagam01@imperial.ac.uk

1 Department of Surgery and Cancer, Imperial College London, Liver Unit, 10th Floor QEQM Building, St Mary's Hospital, London W2 $1 \mathrm{NY}, \mathrm{UK}$

2 Department of Infectious Disease Epidemiology, Imperial College London, London, UK
Globally, 264 million persons are estimated to be chronically infected with hepatitis B virus (HBV). This burden is concentrated primarily in Africa and the Western Pacific regions, with increasing prevalence by decreasing income status of $0.9 \%, 4 \%, 4.4 \%$ and $6.2 \%$, in high-income, upper-middleincome, lower-middle-income and low-income regions, respectively $[1 \bullet \cdot$. Fortunately, there are tools available for HBV infection which encompass both prevention and treatment interventions, but currently no curative therapy. However, these tools are not optimally scaled up in regions where they are most needed. Modelling studies have estimated the intervention coverage levels required to achieve elimination and quantified what impact is theoretically achievable $[2 \cdot \bullet]$. However, how to scale up these interventions to such high levels in an equitable, sustainable and cost-effective manner is challenging, particularly in low-middle-income settings where resources are limited.

\section{Global Successes of Infant Vaccination}

Infant vaccination, which interrupts horizontal transmission (early childhood transmission) was first introduced in the 1980s and has been a WHO recommendation since 1992 . Cost was initially a barrier to universal adoption of such a 
policy, especially low-income countries (LICs). Subsequent dramatic reductions in vaccine price, integration of HBV vaccination into the Expanded Programme on Immunisations (EPI) and funding support from the Global Vaccine Alliance (GAVI) since 2001 for LICs, made scale-up a possibility which has now seen dramatic benefits. By the end of 2017, infant HBV vaccination had been adopted by 187 countries and global coverage with 3 doses was estimated to be $84 \%$.

Many studies have demonstrated the effectiveness of hepatitis B immunisation programmes on reducing hepatitis B surface antigen (HBsAg) prevalence and there are numerous examples of countries in all world regions which have seen decreases in childhood HBsAg prevalence as a result of vaccination introduction [3-5]. On a global scale, modelling studies have suggested that up to 2015 , infant vaccination programmes would have averted 210 million new infections $[2 \bullet \cdot]$. The ultimate aim of reducing HBV infection is to reduce morbidity and mortality due to liver cirrhosis and hepatocellular carcinoma (HCC), but as these complications often take decades to develop, these health outcomes require extended longitudinal follow-up studies. Taiwan and Alaska, two early adopters of comprehensive vaccination programmes in 1984, reported a reduction in the incidence of childhood HCC since their introduction [6-8]. However, a more recent study has highlight that a time trend bias may play an important role in these observed incidence reductions and caution must be exercised in attributing it all to vaccination impact [9].

Unfortunately, in 2018, there still remained 35 countries in the world where infant vaccination coverage was under $80 \%$, including high HBV burden countries like Nigeria which only had $57 \%$ coverage [10]. Furthermore, despite studies showing the proven effectiveness and costeffectiveness of universal infant vaccination [11], debate exists over universal HBV immunisation programmes in some low prevalence countries [12]. For a long time, the UK only targeted at-risk population groups for infant vaccination, mainly due to reasons surrounding lack of cost-effectiveness at low endemicity levels [13] and only recently took the decision to introduce universal HBV infant vaccination into national policy in 2017 [14]. Given changing migration patterns countries should not be complacent in their decisions around $\mathrm{HBV}$ vaccination policy and remain responsive to the needs of the population.

Safety concerns can impact on the acceptance and uptake of vaccines and jeopardise coverage levels, and this has been seen in HBV, for example, in Vietnam and China $[15,16]$. In the case of Vietnam, a perceived association with an increase in sudden infant deaths led to a dramatic fall in HBV vaccination coverage in 2013. A modelling study estimated that this drop in coverage levels would lead to over 17,000 HBV-related deaths [15], emphasising the importance of maintaining high coverage levels.

\section{Prevention of HBV Mother-to-Child Transmission (MTCT): a Remaining Challenge}

\section{The Importance of HBV MTCT in the Elimination Agenda}

Whilst commending the global efforts to scale up HBV infant vaccination over the last three decades, it is vital to acknowledge that this alone will not be sufficient to eliminate new incident HBV infections by 2030 as it does not interrupt transmission occurring from mother-to-child at the time of birth. Since the risk of becoming a chronic carrier of HBV if infected through this route is as high as $90 \%$ [17], prevention of HBV transmission from mother to child during this critical period remains vital. In the pre-vaccination era, it was estimated that in Asia, about $40 \%$ of HBV transmission occurred from mother-to-child, versus $10 \%$ in Africa. However, modelling studies have suggested that due to the successes of infant vaccination, the epidemiology of transmission has changed with a more prominent relative contribution of HBV MTCT in all world regions [2••]. The contribution of HBV MTCT in maintaining ongoing HBV transmission has often been underappreciated in sub-Saharan Africa. However, it is now time to take action as an estimated 350,000 neonates are being infected with HBV annually at birth, a number which represents twice the number of neonatal HIV infections in the region [18••]. Furthermore, data is accumulating to support the hypothesis that those who acquired their infection through MTCT have more severe fibrosis and HCC risk than those acquired horizontally [19-21].

\section{Availability of Safe and Effective HBV PMTCT Interventions}

Three safe and effective interventions are available to combat HBV MTCT: birth dose vaccination (BDV), hepatitis B immunoglobulin (HBIG) and antiviral prophylaxis for HBVinfected mothers with high viral load in the last trimester of pregnancy $[22 \bullet \bullet, 23]$. However, worryingly from a global perspective, the coverage of these interventions falls well below the $90 \%$ coverage levels recommended to reach the WHO hepatitis elimination targets. Data from the Polaris Observatory estimates that only $46 \%$ of infants received timely BDV, $13 \%$ of infants born to HBsAg-positive mothers received HBIG, birth dose and at least two doses of infant vaccination and $<1 \%$ of mothers with high viral load received antiviral treatment in 2016 [1••]. A closer inspection reveals highly heterogenous coverage of HBV PMCT interventions between countries and regions. China, for example, has led the way towards elimination of HBV MTCT by reaching high coverage of infant vaccination, universal timely BDV and HBsAg screening of pregnant women with HBIG to those born to HBsAg positive mothers. This concerted effort has 
reduced under 5-year-old HBsAg prevalence from $9.67 \%$ in 1992 to $0.32 \%$ in 2014, which is a significant achievement [24.0]. Whereas, in sharp contrast in the African region, there is $10 \%$ coverage of timely BD vaccination and only 12 countries have incorporated $\mathrm{BD}$ vaccination into their national policy. Furthermore, most countries in Africa do not offer women systematic HBsAg screening in pregnancy as part of national policy, therefore missing a vital opportunity to offer appropriate interventions. This disparity highlights the need to focus on understanding the key barriers and challenges to intervention scale-up in underperforming regions and focus on how these interventions could be scaled up using an evidencebased strategy which takes into account questions about efficacy, impact and cost-effectiveness.

Universal birth dose vaccination has been a WHO recommendation since 2009 and the advice is that all children receive a dose of $\mathrm{HBV}$ vaccine within $24 \mathrm{~h}$ of birth. Birth dose vaccination has been shown to be effective at reducing HBV MTCT and reduces transmission in hepatitis B e antigen (HBeAg)-positive mothers from about 90 to $15 \%$ and from about $5-30 \%$ to $<0.5 \%$ in HBeAg-negative mothers [18••, 25]. Birth dose vaccination is less effective against MTCT when delayed beyond $24 \mathrm{~h}$ [26]. However, the majority of the data on transmission rates are from studies in Asian or western settings, with a paucity of data from the African region, particularly on MTCT stratified by HBeAg status and viral load or efficacy of birth dose vaccination. The existing studies are often limited by small sample size and heterogeneity in study design $[18 \cdot \bullet]$. Caution needs to be taken when extrapolating transmission and disease progression rates from Asian to African populations, particularly given the differences in viral genotype and host factors [27].

The addition of passive immunisation with HBIG to BDV reduces PMTCT further, particularly in infants born to $\mathrm{HBeAg}$-positive mothers, and is given systematically in high-income settings for all children born to HBsAg-positive mothers. However, its high cost, need for cold chain and associated frequent supply issues makes it an unfeasible option in many LMICs [28]. Furthermore, new data suggests that HBIG does not provide additional protection to BD alone, in infants born to HBeAg mothers with low viral load if BDV is given within $24 \mathrm{~h}$.

Unfortunately, the administration of a timely BDV and HBIG does not completely interrupt MTCT in a subset of HBV-infected mothers and immunoprophylaxis failure is correlated with maternal HBV viral load [29]. Over the last decade, data has been accumulating about the efficacy and safety of peripartum antiviral therapy as a third intervention in addition to $\mathrm{BD}$ and $\mathrm{HBIG}$ to reduce MTCT even further in mothers with the highest risk of transmission $[23,30]$. The 2016 open-labelled randomised trial in China comparing HBV MTCT among HBeAg-positive mothers with HBV viral loads over
$200,000 \mathrm{IU} / \mathrm{ml}$ receiving tenofovir in addition to standard immunisation to those receiving standard immunisation alone provides the strongest evidence to date regarding the effectiveness of this strategy [31]. The intention to treat analysis showed a 5\% HBV MTCT (defined as child positive for HBsAg +/-HBV DNA at 6 months) versus $18 \%(p=0.007)$ and per protocol analysis of 0 compared to $7 \%(p=0.01)$. A more recent study in Thailand showed no significant benefit of addition of maternal antiviral treatment to $\mathrm{BD}$ and $\mathrm{HBIG}$ but was underpowered $[32,33]$. In this study, immunisation was given very early, with a median time of $<1.5 \mathrm{~h}$ after birth, raising the possibility of a potential role of earlier vaccination. However, such a strategy is likely to be even more of a challenge in LMICs and whether the low transmission rate without antiviral therapy can be attributed to very early vaccination needs to be confirmed. The addition of antiviral prophylaxis with tenofovir in pregnancy has been found to be cost-effective in China [34] and, even cost-saving, compared to previous practice of BD and HBIG only in America [35]. Current HBV treatment guidelines including European Association for the Study of the Liver (EASL) and American Association for the Study of the Liver (AASLD) guidelines recommend antiviral treatment in the last trimester of pregnancy in mothers with HBV viral loads over 200,000 IU/ml [36••, 37]. However, the first WHO HBV treatment guidelines were released in 2015, prior to the Pan study, and reported that there was not sufficient high-quality data on the safety and efficacy of antiviral treatment in pregnancy in order to make a formal recommendation at that time [38••]. However, this guideline is currently in the process of being updated. Therefore, from a global perspective, widespread uptake of this strategy is still low and limited to experienced centres where specialist staff and laboratory facilities are available $[1 \bullet \bullet]$.

\section{Barriers and Solutions to Increasing Coverage of Timely Birth Dose Vaccination}

The delivery of timely birth dose vaccination within $24 \mathrm{~h}$ of birth presents a financial and logistical challenge, particularly in sub-Saharan Africa, largely due to the high levels of unassisted births. HBV BDV coverage has been found to correlate with institutional delivery rates and skilled birth attendance rates, both worldwide and in the Africa, South-East Asia and Western Pacific Regions [39]. However, there are many other contributory obstacles including cost of implementation, perceived need for cold chain, low levels of awareness and a lack of systematic integration of the BDV within maternal child health programmes [40]. Lack of outreach programmes to reach out-of-hospital births, BDV given at discharge from health facility and absence of weekend vaccination services were also found to be barriers in a recent multi-centre study in five African countries [41]. Furthermore, in Africa, most 
countries follow a multi-dose vial vaccination policy and this has been found to be a barrier to BDV as is can lead to vaccinator reluctance to open multi-dose vials when there are only a few births occurring in the health facility to avoid wastage of remaining doses [42]. Whether switching to a single-dose monovalent vaccine policy would help overcome this barrier or improved education regarding the importance of a timely BD would suffice remains to be established.

Faced with an ever-expanding portfolio of new emerging childhood vaccines, many low-middle-income countries are understandably struggling to keep up with the recommended pace of implementation of multiple vaccines into their immunisation schedules, particularly without external funding support like in the case of HBV BDV. Despite the low cost of a single dose of HBV vaccine ( $\sim$ US $\$ 0.20$ per dose), successful implementation of a BDV programme incurs additional associated costs including delivery of intervention, cold chain and infrastructure support. The Global Vaccine Alliance (GAVI) who are the biggest global funders of vaccines in low- and middle-income countries have not historically provided universal funding support for the BDV. However, modelling analyses for GAVI's recent Vaccine Investment Strategy estimated that supporting birth dose vaccination scale-up in their funded countries (excluding Nigeria) could avert 1.2-1.5 million future HBV cases to 2035 [43]. GAVI's prioritisation of support of introduction of hepatitis B BDV in their next 2021-2025 strategy is likely to provide significant momentum for countries to introduce and scale up BDV ahead of the 2030 elimination targets.

Increasing the number of assisted births, although a major challenge, forms a key indicator for achieving the Sustainable Development Goal target to reduce maternal mortality and will have many benefits beyond facilitating the delivery of a BD intervention. China provides a good example of a country where increasing the number of health facility-based births successfully contributed to improved BDV coverage rates [44].

The need to ensure cold chain for the HBV vaccination has frequently been cited as a barrier to delivery of a timely $\mathrm{BDV}$, particularly in health facilities where maintaining cold chain is difficult and to reach out-of-hospital births. However, data is now accumulating on the thermostability of HBV vaccines, therefore raising the possibility of a controlled temperature chain (CTC) strategy, which is one that allows vaccines to be kept outside of the cold chain for a limited time period [45]. Although some countries adopt an off-label out-of-cold-chain strategy, a formal CTC licenced HBV vaccine strategy would be welcomed in many countries to help scale up BDV as demonstrated through a survey of 25 countries in the African and Western Pacific regions [42]. Furthermore, the use of a CTC strategy was found to be cost-effective, or even cost-saving in most world regions [46].
A compact prefilled auto-disposable device (CPAD) is an innovative solution which can facilitate the administration of a timely BDV and has been shown to increase coverage rates in studies in Asia and the Western Pacific Region and has been used in Indonesia to reach out-of-hospital births [47]. Although it has been shown to be safe, effective and costsaving when compared to multi-dose vials [48], its widescale uptake is limited by high cost of device and sole manufacturer. The use of the CPAD system by minimally trained health workers has been demonstrated in pilot studies for delivery of other medications and could therefore provide a promising alternative to increase coverage of $\mathrm{BD}$, particularly in rural settings or for out of facility births in the African region - although the feasibility and acceptability of such a strategy needs to be evaluated $[49,50]$.

\section{Implement Systematic Antenatal Screening for HBsAg Among All Pregnant Mothers}

Screening all pregnant women for HBsAg during antenatal care in countries with a population HBV prevalence above $2 \%$ is a WHO recommendation [51••]. However, although high coverage of antenatal testing has been achieved for HIV, many countries still do not incorporate HBsAg screening into national policy, particularly in the African region. This means that many women remain undiagnosed through pregnancy, missing vital opportunities for not only preventing HBV MTCT, but also for case finding and education. The widespread availability of validated low-cost rapid point-ofcare tests for HBsAg means that the addition HBsAg testing should not provide a major incremental burden on health systems [52].

\section{Improve Access to Wide-scale HBV Testing and Treatment}

In 2016, only $10 \%$ of those infected with chronic HBV were estimated to have been diagnosed and only 4.8 million (5\%) of the 94 million eligible for therapy had received antiviral treatment $[1 \bullet \cdot$. Reaching the WHO global target of $80 \%$ coverage of antiviral treatment for all those eligible is therefore going to be an enormous challenge, particularly in low-middle-income settings. Modelling studies highlighted the large global impact that the addition of a test and treat intervention to high prevention could have on HBV-related mortality with the potential to avert 7.3 million deaths by $2030[2 \cdot \bullet]$.

Early diagnosis offers an opportunity to identify those at risk of progression and offer appropriate intervention to reduce complications of liver cirrhosis and liver cancer, as well as an opportunity to allow prevention interventions to reduce the risk of transmission of the virus to others, primarily through PMTCT. 
About $15-40 \%$ of those with chronic hepatitis B (CHB) infection would progress to liver cirrhosis or HCC if left untreated and the primary goal of antiviral therapy is to reduce premature morbidity and mortality due to liver cirrhosis and HCC. Although many studies have demonstrated the efficacy of antiviral therapy, the landmark randomised placebo controlled trial in 2004 by Liaw and colleagues is widely accepted as the best evidence to support the efficacy of nucleos(t)ide analogue therapy in reducing the progression of liver disease from cirrhosis to decompensation and HCC in patients with chronic hepatitis B [53]. HBV DNA levels have been demonstrated to be related to HCC incidence, with data from the REVEAL study showing cumulative HCC incidence rates of $3.57 \%, 12.17$ and $14.89 \%$ if HBV DNA is $>2000,>20,000$ and $>200,000 \mathrm{IU} / \mathrm{ml}$ respectively, during a mean follow-up of 11.4 years [54]. Although the suppression of viral replication is widely agreed to be an important factor in reducing the incidence of HCC, treatment does not eliminate the risk of HCC completely, particularly when cirrhosis has already developed prior to commencement of antiviral therapy as HBV DNA may have already been integrated into the genome [55, 56].

The currently recommended first-line antiviral treatments are tenofovir and entecavir, which are both safe and effective against HBV. Furthermore, there has been no reported tenofovir resistance after 7 years of use [57]. These once daily drug regimens are relatively well accepted and tolerated by patients and a recent systematic review and meta-analysis of data for over 23,000 patients reported an overall adherence rate of $74.6 \%$, which was similar across difference income settings [58].

The cost of tenofovir has dramatically fallen over the last few years and is now available for LMICs to purchase in generic preparation at less than $\$ 40$ per patient per year [59] and many studies have demonstrated the cost-effectiveness of treatment in both high- and low-income settings [60, 61]. However, the current recommendation of lifelong treatment does lead to high cumulative costs which impose a significant financial burden on governments. Therefore, in many countries, access to antiviral treatment for those infected with HBV remains limited and does not form national policy. In China, progress has been made in reduction of drug prices of tenofovir and entecavir through stakeholder engagement and an investment case has shown that providing a comprehensive package of interventions to include testing and treatment would provide a return on investment from a societal perspective [62].

\section{Improving Case Finding for Those Infected with HBV}

The development of low-cost rapid, easy to use point-of-care tests for HBsAg means that testing for HBV infection no longer has to be confined to laboratory settings. Various point-of- care tests now exist and have been confirmed to have high specificity and sensitivity, both in the laboratory and field settings [63]. This ability to provide near patient testing should help facilitate the scale-up of testing as recommended in the WHO Global Hepatitis Sector Strategy. Furthermore, the quick turn-around time allows health workers to immediately relay results to the participant, which can reduce unnecessary follow-up visits and subsequent attrition from the care cascade.

WHO Testing Guidelines recommend that all adults should have routine access to HBsAg testing in settings where general population prevalence is $\geq 2-5 \%$ [51••]. However, careful consideration needs to be given to how case finding is carried out in order to increase yield and in an equitable way, whilst recognising that HBV infection in high burden settings is a general population epidemic; therefore, a model of testing that targets high-risk groups, as has been successful in the case of $\mathrm{HIV}$ or HCV, is not necessarily applicable for HBV.

Opportunistic methods to increase testing for HBV infection include testing in health facilities. This could include when people present at health facilities due to symptoms related to liver disease or a more systematic approach to test all hospital admissions. A pilot opt-out testing for HBV in Emergency Departments (combined with other blood borne virus screening with HIV and $\mathrm{HCV}$ ) was shown to be feasible and effective in identifying new cases in the UK, although with a low uptake [64]. The threshold HBsAg prevalence for such a strategy to be cost-effective in the UK was found to be low at $0.2 \%$ [65]. Testing pregnant women during antenatal screening visits seems the most intuitive testing method with the lowest incremental cost and the potential to have a large prevention impact in terms of reducing onward transmission to the child. However, the immediate benefit to the mothers' individual health is limited as the prevalence of $\mathrm{HBV}$ is lower in young women and they are less likely to have severe disease requiring treatment. Other models to increase diagnosis rates include more active methods which include household testing or mobile clinics, which have been used to various extents in HIV [66]. In the Gambia, a country with an adult population prevalence of $8.8 \%$, an active community-based screening method was found to be feasible and likely to be a cost-effective intervention with the incremental costeffectiveness ratio which was in line with recommended cost-effectiveness thresholds $[60,67 \bullet \bullet]$.

\section{Simplified Strategies for Assessment of Eligibility for Antiviral Treatment and Monitoring}

Not all persons infected with CHB require antiviral treatment and eligibility for treatment is usually evaluated using a combination of measurement of alanine aminotransferase (ALT) levels, HBeAg status, HBV DNA level and an assessment of liver fibrosis. Until 2015, the most widely used international 
HBV guidelines included The European (EASL), American (AASLD) and Asia Pacific (APASL) guidelines [36••, 37, 68]. The proportion of persons fulfilling international treatment criteria for $\mathrm{CHB}$ has been found to vary; $5 \%$ in The Gambia [67••], 10\% in Senegal [69], 25\% in Ethiopia [70••] and 26\% in Germany [71]. This heterogeneity between studies is likely to be explained by study bias in the place of testing or indication for testing, with lower values representing testing in the community where those at earlier stages of disease are diagnosed. This contrasts with hospital cohorts, where most people present at later stages with symptoms or abnormal blood test results.

Recognising the complexity of the existing treatment criteria and the need for multiple, and often costly diagnostics which are often unavailable in LMICs, the 2015 WHO HBV treatment guidelines attempted to simplify and adapt the criteria in order to increase their widespread applicability to settings where resources are limited [38••]. This included a recommendation to use the APRI (aspartate aminotransferase (AST) to platelet ratio index) score with a cut of $>2$ to define cirrhosis and, where HBV DNA was unavailable, an option to treat HBsAg persons based on persistently abnormal ALT levels alone. These were the first WHO HBV treatment guidelines and were widely welcomed. However, at the time of development of these guidelines, the data available were mainly from Asian and Western populations. Subsequent emerging data from patients in the African region now reveal that WHO criteria have low specificity and sensitivity in the African population and are likely to miss people in need of treatment. A recent study assessing $>1000$ patients with $\mathrm{CHB}$ in Ethiopia revealed that using the WHO guidelines would fail to detect half of the patients in need of antiviral therapy [70••]. Furthermore, the use of APRI as a non-invasive marker of liver fibrosis was found to have low diagnostic accuracy in West Africa [72]. It might now therefore be an opportune time to update this guidance in light of new evidence.

Since HBV viral load testing continues to be expensive in many countries and often limited to centralised laboratories in large urban centres, moving away from the reliance on HBV viral load testing for treatment evaluation and monitoring is a promising solution to facilitate the scale-up of treatment. A new simplified algorithm called TREAT-B has been developed for identifying those eligible for treatment [73••]. This has shown that the use of ALT and HBeAg, two simple cheap markers perform well with a sensitivity of $85 \%$ and specificity of $77 \%$ compared to the EASL guidelines in patients in West Africa. Although the score was originally developed among the African population in West Africa, its performance has also been validated in high-income settings of the UK and Germany [74]. Although it is a promising strategy, further work is needed to validate this score in other patient settings.

HBcore-related antigen ( $\mathrm{HBcrAg}$ ) is a biomarker which correlates well with HBV DNA levels and cccDNA [75••,
76]. A recent study has shown good diagnostic accuracy when HBcrAg was used as an alternative to HBV DNA to determine treatment eligibility for patients in The Gambia [77]. Validation of other new diagnostic platforms for HBV DNA quantification including the GeneXpert system which is a lower cost alternative is awaited. Unfortunately, HBeAg rapid tests have recently been shown to have poor diagnostic performance [78]. The development of high-quality rapid tests for both $\mathrm{HBeAg}$ and HBV viral load remain a priority as they would facilitate evaluation for treatment eligibility, as well as antenatal assessment.

With the development of these simplified diagnostics and easy to use non-invasive tools of fibrosis assessment, and in light of the large numbers of cases needed to find and treat, the question emerges as to whether a decentralised model of care would be appropriate for HBV and how this could be implemented in practice, allowing more people living with HBV access to testing and treatment.

\section{Cross Cutting Frameworks to Guide the Elimination Strategy}

\section{Robust Evidence-Based Policy Planning}

In order to meet WHO's elimination targets, strong guidance is needed from a national and international level. The development of carefully constructed national action plans using a robust evidence-based framework is essential. There are promising examples of such collaborative processes and investment cases for viral hepatitis have been developed in countries including China [62], South Africa [79•] and Malaysia [80]. However, more work needs to be done to support countries in planning their response to viral hepatitis.

\section{Integration of Health Systems}

Particularly in the climate of decreased donor funding, innovative solutions are needed as to how viral hepatitis programmes are financed and delivered in effective and cost-effective ways. The solutions to HBV and other diseases should not be siloed. Further, health system research would aid our understanding about how, for example, delivery of HBV interventions can integrate with other health programmes using a more horizontal approach. There are strong synergies with immunisation programmes and maternal and child health programmes which should be utilised. HIV infrastructure in many countries, particularly in Africa, would seem the most obvious resource to leverage as the model of care for delivering HBV treatment and PMTCT interventions has strong parallels with delivery of HIV interventions. 


\section{Early Establishment of Monitoring and Evaluation Systems}

Although it is often easy to concentrate efforts on increasing coverage of interventions, it is important not to forget the vital importance of early establishment of robust monitoring and evaluation frameworks and continued efforts to improve burden estimates. Cross collaborative work between governments, research organisations, international agencies and funders could help improve data collection, especially of cirrhosis deaths, improvement of vital registration and cancer registries and promote the integration of HBV systematically into national surveys like Demographic Health Survey (DHS). Such efforts would help inform the iterative process of refining estimates and projections and tracking progress towards elimination.

As countries move forward, the question is being asked about how country-level elimination efforts are going to be validated. The WHO Western Pacific Region have ambitiously adopted a triple elimination framework for elimination of MTCT of HIV, syphilis and HBV [81]. Performing nationally representative serosurveys to validate the elimination of HBV is not feasible for many countries to perform given the associated resources required, time and cost. Therefore, alternative innovative methods of validation of elimination which combines prevalence data and programmatic coverage data with modelling should be explored further.

\section{Conclusions}

Although progress has been made, in order to reach the elimination targets, an urgent focus needs to be drawn to HBV PMTCT intervention scale-up, particularly in subSaharan Africa and how population level testing and treatment can be increased throughout the world. Innovative outreach strategies, novel biomarkers and the possibility of a functional cure are promising solutions to allow HBV elimination to be reached. However, the importance of careful financing and policy planning, capacity building and establishment of strong surveillance systems should not be underestimated and should not be an afterthought in the road to elimination.

\section{Compliance with Ethical Standards}

Conflict of Interest Shevanthi Nayagam reports consulting fees from the World Health Organization and Pharos Global Health Advisors for the modelling of HBV. Mark Thursz declares no potential conflicts of interest.

Human and Animal Rights This article does not contain any studies with human or animal subjects performed by any of the authors.
Open Access This article is distributed under the terms of the Creative Commons Attribution 4.0 International License (http:// creativecommons.org/licenses/by/4.0/), which permits unrestricted use, distribution, and reproduction in any medium, provided you give appropriate credit to the original author(s) and the source, provide a link to the Creative Commons license, and indicate if changes were made.

\section{References}

Papers of particular interest, published recently, have been highlighted as:

- Of importance

•. Of major importance

1.• Razavi-Shearer D, Gamkrelidze I, Nguyen MH, Chen D-S, Van Damme P, Abbas Z, et al. Global prevalence, treatment, and prevention of hepatitis B virus infection in 2016: a modelling study. Lancet Gastroenterol Hepatol. 2018;3(6):383-403. An global modelling study estimating the prevalence of $\mathrm{HBsAg}$ and the coverage of interventions.

2.• Nayagam S, Thursz M, Sicuri E, Conteh L, Wiktor S, Low-Beer D, et al. Requirements for global elimination of hepatitis B: a modelling study. Lancet Infect Dis. 2016;16(12):1399-408. A modelling study evaluating what impact could be achieved by scale-up of key prevention and treatment interventions against $\mathrm{HBV}$, on a global level.

3. Liang X, Bi S, Yang W, Wang L, Cui G, Cui F, et al. Epidemiological serosurvey of hepatitis B in China-declining HBV prevalence due to hepatitis B vaccination. Vaccine. 2009;27(47):6550-7.

4. Whittle HC, Maine N, Pilkington J, Mendy M, Fortuin M, Bunn J, et al. Long-term efficacy of continuing hepatitis $B$ vaccination in infancy in two Gambian villages. Lancet. 1995;345(8957):1089-92.

5. Ng KP, Saw TL, Baki A, Rozainah K, Pang KW, Ramanathan M. Impact of the expanded program of immunization against hepatitis B infection in school children in Malaysia. Med Microbiol Immunol. 2005;194(3):163-8.

6. Chang MH, You SL, Chen CJ, Liu CJ, Lee CM, Lin SM, et al. Decreased incidence of hepatocellular carcinoma in hepatitis B vaccinees: a 20-year follow-up study. J Natl Cancer Inst. 2009;101(19):1348-55.

7. Chang M-H, Chen C-J, Lai M-S, Hsu H-M, Wu T-C, Kong M-S, et al. Universal hepatitis B vaccination in Taiwan and the incidence of hepatocellular carcinoma in children. N Engl J Med. 1997;336(26):1855-9.

8. McMahon BJ, Bulkow LR, Singleton RJ, Williams J, Snowball M, Homan C, et al. Elimination of hepatocellular carcinoma and acute hepatitis B in children 25 years after a hepatitis B newborn and catch-up immunization program. Hepatology. 2011;54(3):801-7.

9. Chang CH, Lin JW, Tu YK. Secular trends were considered in the evaluation of universal hepatitis B vaccination in Taiwan. J Clin Epidemiol. 2015;68(4):405-11.

10. WHO/UNICEF Estimates of National Immunization Coverage (WUENIC). Geneva: World Health Organization. Update of 15 Jul 2019. Available from: https://apps.who.int/immunization monitoring/globalsummary/timeseries/tswucoveragehepb3.html. Last accessed 21 Jul 2019.

11. Beutels P. Economic evaluations of hepatitis B immunization: a global review of recent studies (1994-2000). Health Econ. 2001;10(8):751-74. 
12. Damme PV, Leuridan E, Hendrickx G, Vorsters A, Theeten H, Leino T, et al. Should Europe have a universal hepatitis B vaccination programme? BMJ. 2013;347.

13. Siddiqui MR, Gay N, Edmunds WJ, Ramsay M. Economic evaluation of infant and adolescent hepatitis B vaccination in the UK. Vaccine. 2011;29(3):466-75.

14. Mandal S. Introduction of universal infant hepatitis B immunisation in the UK- paving the way to elimination. Hum Vaccin Immunother. 2019;15(2):440-3.

15. Li X, Wiesen E, Diorditsa S, Toda K, Duong TH, Nguyen LH, et al. Impact of adverse events following immunization in Viet Nam in 2013 on chronic hepatitis B infection. Vaccine. 2016;34(6):869-73.

16. Yu W, Liu D, Zheng J, Liu Y, An Z, Rodewald L, et al. Loss of confidence in vaccines following media reports of infant deaths after hepatitis B vaccination in China. Int J Epidemiol. 2016;45(2):441-9.

17. Edmunds WJ, Medley GF, Nokes DJ, Hall AJ, Whittle HC. The influence of age on the development of the hepatitis B carrier state. Proc Biol Sci. 1993;253(1337):197-201.

18.• Keane E, Funk AL, Shimakawa Y. Systematic review with metaanalysis: the risk of mother-to-child transmission of hepatitis B virus infection in sub-Saharan Africa. Aliment Pharmacol Ther. 2016;44(10):1005-17. Important systematic review looking at mother-to-child transmission studies in Africa.

19. Shimakawa Y, Lemoine M, Bottomley C, Njai HF, Ndow G, Jatta $\mathrm{A}$, et al. Birth order and risk of hepatocellular carcinoma in chronic carriers of hepatitis B virus: a case-control study in The Gambia. Liver Int. 2015;35:2318-26.

20. Shimakawa Y, Lemoine M, Njai HF, Bottomley C, Ndow G, Goldin RD, et al. Natural history of chronic HBV infection in West Africa: a longitudinal population-based study from The Gambia. Gut. 2016;65(12):2007-16.

21. Shimakawa Y, Yan HJ, Tsuchiya N, Bottomley C, Hall AJ. Association of early age at establishment of chronic hepatitis B infection with persistent viral replication, liver cirrhosis and hepatocellular carcinoma: a systematic review. PLoS One. 2013;8(7): e69430.

22.• Pan CQ, Duan Z, Dai E, Zhang S, Han G, Wang Y, et al. Tenofovir to prevent hepatitis B transmission in mothers with high viral load. N Engl J Med. 2016;374(24):2324-34. Important trial comparing addition of Tenofovir to standard immunoprophylaxis on mother-to-child transmission rates in China.

23. Hyun MH, Lee YS, Kim JH, Je JH, Yoo YJ, Yeon JE, et al. Systematic review with meta-analysis: the efficacy and safety of tenofovir to prevent mother-to-child transmission of hepatitis B virus. Aliment Pharmacol Ther. 2017;45(12):1493-505.

24.• Cui F, Shen L, Li L, Wang H, Wang F, Bi S, et al. Prevention of chronic hepatitis B after 3 decades of escalating vaccination policy, China. Emerg Infect Dis. 2017;23(5):765-72. This article presents the results of the 2014 national HBV serosurvey in China and provides a good summary of the remarkable achievement that the scale-up of HBV immunisation programmes has had on reducing HBsAg prevalence in China.

25. Chen HL, Lin LH, Hu FC, Lee JT, Lin WT, Yang YJ, et al. Effects of maternal screening and universal immunization to prevent mother-to-infant transmission of HBV. Gastroenterology. 2012;142(4):773-81. e2.

26. Marion SA, Tomm Pastore M, Pi DW, Mathias RG. Long-term follow-up of hepatitis B vaccine in infants of carrier mothers. Am J Epidemiol. 1994;140(8):734-46.

27. Lin C-L, Kao J-H. The clinical implications of hepatitis B virus genotype: recent advances. J Gastroenterol Hepatol. 2011;26:123-30.

28. Hepatitis B vaccines: WHO position paper - July 2017. Wkly Epidemiol Rec. 2017;92(27):369-92.

29. Wen W-H, Chang M-H, Zhao L-L, Ni Y-H, Hsu H-Y, Wu J-F, et al. Mother-to-infant transmission of hepatitis B virus infection: significance of maternal viral load and strategies for intervention. J Hepatol. 2013;59(1):24-30.

30. Brown RS, McMahon BJ, Lok ASF, Wong JB, Ahmed AT, Mouchli MA, et al. Antiviral therapy in chronic hepatitis B viral infection during pregnancy: a systematic review and meta-analysis. Hepatology. 2016;63(1):319-33.

31. Pan CQ, Duan Z, Dai E, Zhang S, Han G, Wang Y, et al. Tenofovir to prevent hepatitis B transmission in mothers with high viral load. N Engl J Med. 2016;374(24):2324-34.

32. Jourdain G, Ngo-Giang-Huong N, Harrison L, Decker L, Khamduang W, Tierney C, et al. Tenofovir versus placebo to prevent perinatal transmission of hepatitis B. N Engl J Med. 2018;378(10):911-23.

33. Terrault NA, Feld JJ, Lok ASF. Tenofovir to prevent perinatal transmission of hepatitis B. N Engl J Med. 2018;378(24):2348-9.

34. Cui F, Woodring J, Chan P, Xu F. Considerations of antiviral treatment to interrupt mother-to-child transmission of hepatitis B virus in China. Int J Epidemiol. 2018;47(5):1529-37.

35. Fan L, Owusu-Edusei K Jr, Schillie SF, Murphy TV. Costeffectiveness of active-passive prophylaxis and antiviral prophylaxis during pregnancy to prevent perinatal hepatitis B virus infection. Hepatology. 2016;63(5):1471-80.

36.• EASL. 2017 Clinical practice guidelines on the management of hepatitis B virus infection. J Hepatol. 2017;67(2):370-98. Latest European guidelines on management of hepatitis B infection.

37. Terrault NA, Bzowej NH, Chang KM, Hwang JP, Jonas MM, Murad MH. AASLD guidelines for treatment of chronic hepatitis B. Hepatology. 2016;63(1):261-83.

38.• WHO Guidelines Approved by the Guidelines Review Committee. Guidelines for the prevention, care and treatment of persons with chronic hepatitis B infection. Geneva: World Health Organization; 2015. Copyright (c) World Health Organization 2015. First guidelines developed by the World Health Organization providing evidence-based guidance for the management of hepatitis $B$.

39. Allison RD, Patel MK, Tohme RA. Hepatitis B vaccine birth dose coverage correlates worldwide with rates of institutional deliveries and skilled attendance at birth. Vaccine. 2017;35(33):4094-8.

40. World Health Organization (2012). Practices to improve coverage of the hepatitis B birth dose vaccine. World Health Organization. https://apps.who.int/iris/handle/10665/78616

41. Moturi E, Tevi-Benissan C, Hagan JE, Shendale S, Mayenga D, Murokora D, et al. Implementing a birth dose of hepatitis B vaccine in Africa: findings from assessments in 5 countries. J Immunol Sci. 2018;Suppl(5):31-40.

42. Petit D, Tevi-Benissan C, Woodring J, Hennessey K, Kahn A-L. Countries' interest in a hepatitis B vaccine licensed for the controlled temperature chain; survey results from African and Western Pacific regions. Vaccine. 2017;35(49, Part B):6866-71.

43. GAVI The Vaccine Alliance. Vaccine investment strategy. Investment Case: hepatitis B birth dose https://www.gavi.org/about/strategy/ vaccine-investment-strategy/. Accessed 21 Jul 2019.

44. Cui F, Li L, Hadler SC, Wang F, Zheng H, Chen Y, et al. Factors associated with effectiveness of the first dose of hepatitis $B$ vaccine in China: 1992-2005. Vaccine. 2010;28(37):5973-8.

45. WHO. A systematic review of monovalent hepatitis B vaccine thermostability. Geneva: World Health Organization; 2017.

46. Scott N, Palmer A, Morgan C, Lesi O, Spearman CW, Sonderup M, et al. Cost-effectiveness of the controlled temperature chain for the hepatitis B virus birth dose vaccine in various global settings: a modelling study. Lancet Glob Health. 2018;6(6):e659-e67.

47. Sutanto A, Suarnawa IM, Nelson CM, Stewart T, Soewarso TI. Home delivery of heat-stable vaccines in Indonesia: outreach immunization with a prefilled, single-use injection device. Bull World Health Organ. 1999;77(2):119-26. 
48. Levin CE, Nelson CM, Widjaya A, Moniaga V, Anwar C. The costs of home delivery of a birth dose of hepatitis B vaccine in a prefilled syringe in Indonesia. Bull World Health Organ. 2005;83(6):456-61.

49. Diop A, Daff B, Sow M, Blum J, Diagne M, Sloan NL, et al. Oxytocin via Uniject (a prefilled single-use injection) versus oral misoprostol for prevention of postpartum haemorrhage at the community level: a cluster-randomised controlled trial. Lancet Glob Health. 2016;4(1):e37-44.

50. Guillermet E, Dicko HM, Mai LTP, N'Diaye M, Hane F, Ba SO, et al. Acceptability and feasibility of delivering pentavalent vaccines in a compact, prefilled, autodisable device in Vietnam and Senegal. PLoS One. 2015;10(7):e0132292.

51.• WHO Guidelines Approved by the Guidelines Review Committee. WHO Guidelines on Hepatitis B and C Testing. Geneva: World Health Organization. Copyright (c) World Health Organization; 2017. Guidelines developed by WHO on testing strategies for increasing diagnosis for viral hepatitis.

52. Njai HF, Shimakawa Y, Sanneh B, Ferguson L, Ndow G, Mendy $\mathrm{M}$, et al. Validation of rapid point-of-care (POC) tests for detection of hepatitis B surface antigen in field and laboratory settings in the Gambia. West Afr J Clin Microbiol. 2015;53(4):1156-63.

53. Liaw Y-F, Sung J, Chow W, Farrell G, Lee C-Z, Yuen H, et al. Lamivudine for patients with chronic hepatitis B and advanced liver disease. N Engl J Med. 2004;351(15):1521-31.

54. Chen CJ, Yang HI, Su J, Jen CL, You SL, Lu SN, et al. Risk of hepatocellular carcinoma across a biological gradient of serum hepatitis B virus DNA level. Jama. 2006;295(1):65-73.

55. Papatheodoridis GV, Manolakopoulos S, Touloumi G, Vourli G, Raptopoulou-Gigi M, Vafiadis-Zoumbouli I, et al. Virological suppression does not prevent the development of hepatocellular carcinoma in $\mathrm{HBeAg-negative} \mathrm{chronic} \mathrm{hepatitis} \mathrm{B} \mathrm{patients} \mathrm{with} \mathrm{cirrhosis}$ receiving oral antiviral(s) starting with lamivudine monotherapy: results of the nationwide HEPNET. Greece cohort study. Gut. 2011;60(8):1109-16.

56. Wong GL, Chan HL, Mak CW, Lee SK, Ip ZM, Lam AT, et al. Entecavir treatment reduces hepatic events and deaths in chronic hepatitis B patients with liver cirrhosis. Hepatology. 2013;58(5): 1537-47.

57. Buti M, Tsai N, Petersen J, Flisiak R, Gurel S, Krastev Z, et al. Seven-year efficacy and safety of treatment with Tenofovir Disoproxil fumarate for chronic hepatitis B virus infection. Dig Dis Sci. 2015;60(5):1457-64.

58. Ford N, Scourse R, Lemoine M, Hutin Y, Bulterys M, Shubber Z, et al. Adherence to Nucleos(t)ide analogue therapies for chronic hepatitis B infection: a systematic review and meta-analysis. Hepatol Commun. 2018;2(10):1160-7.

59. Hutin Y, Nasrullah M, Easterbrook P, Nguimfack BD, Burrone E, Averhoff F, et al. Access to treatment for hepatitis B virus infection worldwide, 2016. MMWR Morb Mortal Wkly Rep. 2018;67(28): 773-7.

60. Nayagam S, Conteh L, Sicuri E, Shimakawa Y, Suso P, Tamba S, et al. Cost-effectiveness of community-based screening and treatment for chronic hepatitis B in The Gambia: an economic modelling analysis. Lancet Glob Health. 2016;4(8):e568-e78.

61. Dan Y, Wong J, Hamid S, Han K-H, Jia J, Liu C-J, et al. Consensus cost-effectiveness model for treatment of chronic hepatitis B in Asia Pacific countries. Hepatol Int. 2014;8(3):382-94.

62. Nayagam S, Chan P, Zhao K, Sicuri E, Wang X, Jia J, et al. Investment case for a comprehensive package of interventions against hepatitis B in China. J Hepatol. 2016;64(2):S469.

63. Chevaliez S, Pawlotsky J-M. New virological tools for screening, diagnosis and monitoring of hepatitis $\mathrm{B}$ and $\mathrm{C}$ in resource-limited settings. J Hepatol. 2018;69(4):916-26.

64. Bradshaw D, Rae C, Rayment M, Turner N, Turner R, Pickard G, et al. HIV/HCV/HBV testing in the emergency department: a feasibility and seroprevalence study. HIV Med. 2018;19(Suppl 1):52-7.
65. Williams J, Vickerman P, Douthwaite S, Nebbia G, Hunter L, Wong T, et al. THU-435-a threshold analysis for the cost-effectiveness of hepatitis B and hepatitis $\mathrm{C}$ testing in emergency departments in the UK. J Hepatol. 2019;70(1):e348-e9.

66. Suthar AB, Ford N, Bachanas PJ, Wong VJ, Rajan JS, Saltzman AK, et al. Towards universal voluntary HIV testing and counselling: a systematic review and meta-analysis of community-based approaches. PLoS Med. 2013;10(8):e1001496.

67.• Lemoine M, Shimakawa Y, Njie R, Taal M, Ndow G, Chemin I, et al. Acceptability and feasibility of a screen-and-treat programme for hepatitis B virus infection in The Gambia: the prevention of liver fibrosis and Cancer in Africa (PROLIFICA) study. Lancet Glob Health. 2016;4(8):e559-67. Important research study evaluating an outreach community method of screening and treatment for hepatitis $B$ in a high endemic country in sub-Saharan Africa.

68. Sarin SK, Kumar M, Lau GK, Abbas Z, Chan HL, Chen CJ, et al. Asian-Pacific clinical practice guidelines on the management of hepatitis B: a 2015 update. Hepatol Int. 2016;10(1):1-98.

69. Jaquet A, Nouaman M, Tine J, Tanon A, Anoma C, Inwoley A, et al. Hepatitis B treatment eligibility in West Africa: uncertainties and need for prospective cohort studies. Liver Int. 2017;37(8): 1116-21.

70.• Aberra H, Desalegn H, Berhe N, Mekasha B, Medhin G, Gundersen SG, et al. The WHO guidelines for chronic hepatitis $\mathrm{B}$ fail to detect half of the patients in need of treatment in Ethiopia. J Hepatol. 2019;70(6):1065-71. An important study comparing European and WHO treatment guidelines in selecting patients for antiviral therapy in a hepatitis B cohort in Ethiopia.

71. Post G, Shalev N, Baumgarten A, Shimakawa Y, Lemoine M, Krznaric I, et al. Indication for treatment and severity of disease in treatment-naive patients with chronic hepatitis B virus infection. Eur J Gastroenterol Hepatol. 2019;31(6):723-8.

72. Lemoine M, Shimakawa Y, Nayagam S, Khalil M, Suso P, Lloyd $\mathrm{J}$, et al. The gamma-glutamyl transpeptidase to platelet ratio (GPR) predicts significant liver fibrosis and cirrhosis in patients with chronic HBV infection in West Africa. Gut. 2016;65(8): 1369-76.

73.• Shimakawa Y, Njie R, Ndow G, Vray M, Mbaye PS, Bonnard P, et al. Development of a simple score based on HBeAg and ALT for selecting patients for HBV treatment in Africa. J Hepatol. 2018;69(4):776-84. A study looking at the performance of a simple HBV DNA free algorithm for selecting patients in need of antiviral therapy.

74. Yoshida K, Post G, Shimakawa Y, Thursz M, Brown A, Ingiliz P, et al. Clinical utility of TREAT-B score in African and non-African HBV-infected patients living in Europe. J Hepatol. 2019;70(6): 1295-7.

75.• Honer Zu Siederdissen C, Maasoumy B, Cornberg M. New viral biomarkers for Hepatitis B: are we able to change practice? J Viral Hepat. 2018;25(11):1226-35. Important review on the use of novel biomarkers for hepatitis B infection including HBcorerelated antigen and HBV RNA.

76. Mak LY, Wong DK, Cheung KS, Seto WK, Lai CL, Yuen MF. Review article: hepatitis B core-related antigen (HBcrAg): an emerging marker for chronic hepatitis B virus infection. Aliment Pharmacol Ther. 2018;47(1):43-54.

77. Shimakawa Y, Ndow G, Njie R, Njai HF, Takahashi K, Akbar SMF, et al. Hepatitis B core-related antigen ( $\mathrm{HBcrAg})$ : an alternative to HBV DNA to assess treatment eligibility in Africa. Clin Infect Dis. 2019. https://doi.org/10.1093/cid/ciz412.

78. Seck A, Ndiaye F, Maylin S, Ndiaye B, Simon F, Funk AL, et al. Poor sensitivity of commercial rapid diagnostic tests for hepatitis B e antigen in Senegal, West Africa. Am J Trop Med Hyg. 2018;99(2):428-34.

79. Hecht R, Hiebert L, Spearman WC, Sonderup MW, Guthrie T, Hallett TB, et al. The investment case for hepatitis B and C in 
South Africa: adaptation and innovation in policy analysis for disease program scale-up. Health Policy Plan. 2018;33(4):528-38.

Article on an investment case to support the development of the South African national hepatitis action plan.

80. Hiebert L, Hecht R, Soe-Lin S, Mohamed R, Shabaruddin FH, Syed Mansor SM, et al. A stepwise approach to a National Hepatitis C Screening Strategy in Malaysia to meet the WHO 2030 targets: proposed strategy, coverage, and costs. Value Health Reg Issues. 2019;18:112-20.
81. World Health Organization, Western Pacific Region. Regional framework for the triple elimination of mother-to-child transmission of HIV, hepatitis B and syphilis in Asia and the Pacific, 20182030. World Health Organization 2018. Available at https://iris. wpro.who.int/bitstream/handle/10665.1/14193/9789290618553eng.pdf. Accessed 21 Jul 2019.

Publisher's Note Springer Nature remains neutral with regard to jurisdictional claims in published maps and institutional affiliations. 